\title{
Dwindling Academic Performance of Secondary School Students in Enugu State Nigeria: Diagnosing Teacher-Student Relationship for Therapy
}

\author{
Emma E. O. Chukwuemeka \\ Department of Public Administration \\ Nnamdi Azikiwe University Awka Nigeria \\ Email: ee.chukwuemeka@unizik.edu.ng \\ Mathias Ananti \\ Department of Public Administration \\ Chukwuemeka Odumegwu Ojukwu University \\ Igbariam Campus \\ Rose Onyekwelu \\ Department of Public Administration, Chukwuemeka \\ Odumegwu Ojukwu University, Igbariam
}

$\begin{array}{ll}\text { Received: December 12, } 2019 & \text { Accepted: December 29, } 2019 \quad \text { Published: January 21, } 2020 \\ \text { doi:10.5296/ijrd.v6i2.16314 } & \text { URL: http://dx.doi.org/10.5296/ijrd.v6i2.16314 }\end{array}$

\begin{abstract}
One of the purest, deeply and inspirational relationships is that of a devoted teacher and willing students. Almost everyone has a favorite and those we liked less, it totally depends on how the student-teacher relationship were developed, nurtured and given space to evolve. Currently the academic performance of students in secondary schools has dropped inexorably across the Country. Enugu State not excluded. The study therefore examined the effect of teacher-students relationship on the academic performance of senior secondary school students in selected secondary schools of Enugu State. It is a descriptive study. Four research questions were raised to guide the study. The tools used to elicit data from respondents were questionnaire, face to face interview, observation
\end{abstract}


and focus group discussion guide. The data collected were analyzed using mean. The population of the study is 1520 comprising teachers, principals and students in the three selected secondary schools in Aninri Local Government Area. Taro Yamani sample selection formula was used to select a sample size of seven hundred and sixty respondents. The findings revealed that teacher-student relation affects positively or adversely academic performance of students, teacher-student relation is bedeviled by challenges and there are strategies which should be adopted to strengthen teacher-student relation. Based on these findings, appropriate recommendations such as supervision of instruction, workshop and advocacy were among the measures proffered.

Keywords: Teacher, Student, academic performance, Psychological reorientation

\section{Introduction}

Today the purpose of the teacher is not just to teach the students to pass examinations but also the teacher takes on the role of organizing, managing, counselling, observing and evaluating (Lee, 2016) and in order to be successful in his goals and objectives, the teacher has to involve the student through commitment and by developing an association with the student (Baker, 2006). The Teacher is the most important element in education and teaching activities (Huges J, Gleason $\mathrm{K}$, \& Zhang O 2005). Usually teacher is a person working in educational institute who facilitates the students to achieve cognitive sensory and behavioral aim and gains within the range determined by the educational system (Gundogdu \& Silman, 2007)

Traditionally teacher-student relationships were based on usual traditional thinking that the teachers have the basic authority and know what is best for students, students were viewed as inactive recipients of knowledge who always say yes to academic demands without questioning (Baker, 2018).

Total power was in the hands of the teacher who makes unilateral judgements of student performance and decides which experiences will occur (Tanner, 1990). Students were expected to function from an obedience model, remaining dependent on the teacher.

But this was creating hinderances in the cognitive and behavioral development of the student (Grossman and MacDonald, 2018). That is why many scholars have emphasized to eliminate this authoritative attitude of teachers and focused on the importance of Positive Teacher-Student Relationship (Wentzel, 2017). Although there is a considerable amount of research carried out on positive teacher-student relationship but these studies usually were not designed to describe changes across the teaching career. Substantial body of research demonstrates the importance of teacher-students relation. From the teacher's perspective, it is revealed that teacher-student relation has correlation with student's high academic achievement, pro-social behavior, school adjustment and mediated students' later school success (Midgley, Feldlaufer and Eccles 1989, Itamre \& Piants, 2001; Parats \& Stuhlman, 2004).

Subsequently, the studies of teacher-student's perspective demonstrate that students have an acute understanding and how these relationships influence classroom participation and attitude towards learning (Wentzel, 1997, Roeser, Eccles and Samer 2000; and Raider Roth, 2005).

Significantly, the quality of teacher-student relationship is important for children who experience 
social, emotional and academic difficulties (Lynch and Cicchetti, 2003 and Juvoneni, 2006). In other words, teacher's relation with his or her learners is critical to educational development. Furthermore, more recent studies demonstrate the importance of the student-teacher relationship, there are several gaps that need to be addressed to better understand how relationship benefits a student's academic outcomes (Teffrey, 2016). Thus, the student-teacher relationship research that has examined academic success has failed to be consistent with definitions of "academic outcomes" and methods for measuring academic success. In defining the dependent variable of "academic outcomes", different researchers consider different variables as measures of success. (Hamre and Piants, 2015). Consider for example the following definitions of academic outcomes: (a) grades, (b) achievement test scores etc. Because there are many different definitions of academic outcome, it is difficult to compare findings across studies other than to note the direction of relationship. (Piants, et al., 2014; Lynch \& Ciechetti, 2017).

Therefore, this study intends to explore the variations, impediments and environmental variables faced by secondary school teachers in the selected secondary schools in Aninri Local Government Area of Enugu State which inhibit them from building and sustaining positive teacher-student relationship.

\subsection{Statement of the Problem}

Over the past five decades, the Nigerian government has expressed commitment to the issue of eradicating illiteracy by universalizing basic education. Universal Basic Education (UBE) program is a reform measure which aims to address inequality and quality in level of all school age children nation-wide. But it seems that there is general outcry that standard of education is falling and morals are flagging. Some blame students for this apparent decline in the quality of education and moral values. Some teachers were blamed for the woes in our schools that they are not as devoted and dedicated to the cause of education as their predecessor in the $20^{\text {th }}$ century, while teachers as a group blame parents and children. (Adebayo, 2015).

Succinctly, there were also unpleasant incidences in the relationship between teachers and students. For instance, there were cases of victimization, insults and abuses, bullying of students by teachers. (Udeh, 2014). Thus, secondary schools in Enugu State were not exception to this ugly incidence. To this end, this study explores the nature of relationship between teachers and students and its effects on academic performance. When the student does not feel secure and safe in his learning environment he tends to dread going to school and this also impairs understanding of subjects taught. When learning environment is cordial, it provides scaffolding for social and academic skill. Teachers who support students in learning environment can positively impact on their academic outcomes which are important for long term trajectory of academic achievement and eventually employment. Another factor worthy of investigation is the case of students who are uncompromising, recalcitrant and stubborn. Teachers in cases like this may be apt to counsel such students but the stubborn and uncompromising attitude of such students deter the teachers, thus making the teachers appear indifferent. Situations like this also breed hatred. A cursory look at most secondary schools in Enugu State indicates that lateness to school and absenteeism is common among students, especially students who have aversion for their teachers. 


\subsection{Research Questions}

This study is guided by the following research questions:

1. To what extent is teachers' bully on students affect their cordial relationship and subsequent dwindling academic performance

2. What are the effects of teacher-student relation on academic performance of students in secondary schools in Aninri Local Government Area?

3. To what extent is the students uncompromising attitude affect their relationship with their teachers?

\section{Review of Related Literature}

\subsection{The Concept of Teacher and Teaching}

A teacher is an instructor of knowledge, skills and competence. However, the concept elicits diverse definitions that portend to common meaning. Accordingly, Eya and Igbokwe (1999) defined a teacher as an instructor, school master, preceptor, tutor, professor, pedagogue, educationist, educator, school-mistress, who:

(i) show how to do something

(ii) give lessons to a student or pupil

(iii) give lessons in a subject or hold classes in the subject

(iv) provide knowledge or insight

In other words, a teacher imparts, directs, instructs, informs, counsels admonishes, educates, inculcates, enlightens, advises, trains and indoctrinates. Sequeira (2012) remarked that teaching is a set of events, outside the learner.

\subsection{Role of the Teacher}

Generally, the role of teacher can be categorized into:

1) Traditional Role - Teacher centered

2) Modern Role-facilitator (student centered)

Furthermore, Awojobi (1978) identifies four classifications of teachers to include:

(a) Nursery or pre-primary school teachers

(b) Primary school teachers

(c) Post-primary school teachers

(d) Tertiary school teachers

Teaching as indicated is a task consisting of discrete skills as well as content. This makes teaching complete and the training of teachers in pedagogy and arduous task (NTI, 2009). Teaching is one 


\section{Mll Macrothink}

International Journal of Regional Development

ISSN 2373-9851

2019, Vol. 6, No. 2

of the oldest professions. It is also one of the most important and difficult jobs in the world (Eya \& Igbokwe, 1999).

\subsection{Concept of Learning}

Learning is about a change. The change that brought about by developing a new skill, understanding a scientific law, changing attitude etc. The change is not merely incidental or natural in the way that our appearance changes as we get older.

Learning is a relatively permanent change usually brought about intentionally. When we attend a course, search through a book or read a discussion paper, we set out to learn (Segueira, 2012).

Learning theories

- The Behaviorist (behaviorism stimulus - response)

- The New-Behaviorists (Neo-behaviorism; Human mind)

- $\quad$ The Guestlists (insight)

- The Cognitivists (cognitive development: learning to think)

- The Humanists (active nature of learner)

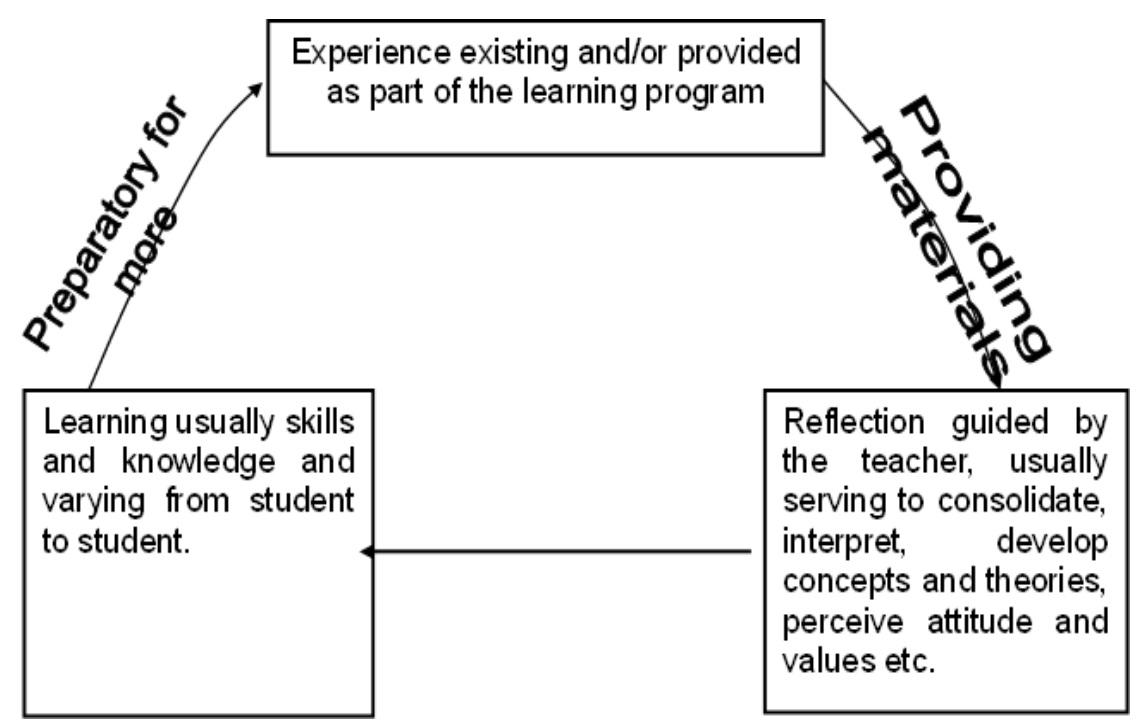

Figure1. Experience, Reflection learning model to optimize learning

Source: Lan Reece and Stephen Walker (2010).

Furthermore, teaching and learning is relational. Thus, the realization of the fundamental purpose that propel this formal interaction is a function of cordiality. Hence, the effectiveness of teaching and enhanced learning process is facilitated by teacher - student relation.

\subsection{The Concept of Teacher-Student Relation}

Research on teacher-student relationship defines high-quality or good teacher-student relationship 
as having high levels of closeness (Davis, 2003; McCornick, 2013, \& White, 2013). Hence, such a relationship is characterized by affection, warmth and open communication between student and teacher (Piants, 2001).

Subsequently, the description of a good teacher-student relationship as close (Newberry and Davis, 2008, Piants, 2001). Literature uses adjectives such as supportive (Baker, 2016, Newberry, 2010, Davis, 2016), positive (Liew 2010, Newberry, 2010) and caring (Aultman, 2009; Noddings, 2015). In other words, teacher-student relation is relation between the teacher and learner. It is good relation with reference to cordial and open interaction and communication. Studies have shown that strong relationships between a teacher and his/her students have a substantial impact on academic success. When students view their teachers as a partner rather than an adversary, they are more open to learning (Noddings, 2015). He also argues that positive relationships result in better experience for the child, a more productive learning environment, and higher academic achievements.

Significantly, the emotional dimension of teaching is reflected in this definition of relationship defined as state of connectedness between people, especially an emotional correction (Webster Dictionary, 2014). Thus, a teacher-student relationship can be described as the emotional bond student and teacher share with each other (Newberry \& Davis, 2008, p. 4) where the quality of the relationship is determined by how strong the bond is. Both student and teacher characteristics can shape and change the quality of relationship (Sabol \& Piants, 2012). Basically, there is a correlation between teacher-student relation with academic performance. Thus, it has been established through empirical research that one of the benefits of teacher-student relation is academic performance or achievement. Hence, the teacher-student relation reflects on:

(i) Open communication on the challenges or difficulties of the learner

(ii) Closeness between the teacher and students within and outside the school system by mutual respect, tolerance and ethics

\subsection{The Role of Teacher in Classroom}

According to Whitaker (2013), the main variable in the classroom is not the student but the teacher. Great teachers have high expectations for their students, but even higher expectations for themselves. These teachers recognize the importance of connecting with their students, that if they are unable to connect with them emotionally then influencing their minds may be impossible.

Good teachers put snags in the river of children passing by, and over time, they redirect hundreds of lives. There is an innocence that conspires to hold humanity together..."(Bolman and Deal, 2015).

Whitaker (2017) suggests that teachers are the first and perhaps most important point of contact in a student's life. Despite the countless reforms, educational movements, and programs implemented to improve education, no other element can be as profound as the human element. He urges, "It's the people, not the programs".

A fundamental question for a student is "Does my teacher like me?" Given a rigorous, aligned curriculum, the answer to that simple question is our best predictor of student achievement (Terry, 
2018).

\subsubsection{Role of Both Student and Teacher}

Teacher knowledge and efficacy of student's motivation and achievement are crucial components to creating relationships that motivate. Both teachers and students have to value their contribution. A student has to feel worthwhile and a appreciated. A teacher needs to recognize that he or she can have a positive effect on their students. Wiseman and Hunt (2005) refer to this as "teacher efficacy" and note that the more the teacher believes in this, the more they will cause it to happen.

\subsubsection{A Psychological Effects of Student- Teacher Relationship on Students}

Students are influenced by perceptions of their teacher's even handedness. Competence, caring and support as well as the nature of the teacher-student relationship are pre-requisite for pragmatic results. A student wants tp feel connected to people and to feel as though he or she deserves top be loved and respected (Stipek, 2005). According to Stipek (2005), many of the students who are not doing well academically, are the same people who have poor relationship with their teachers. Typically, the more they lag behind academically, often, more this relationship is weakened, if the students are lukewarm. Hunt (2005) supports the idea that a good teacher-student relationship positively influences learning. The more connected a student feels, the more he is willing to attempt tasks and to seek help when necessary. The student who feels this sense of connectedness may want to maintain it or please the teacher by doing well in class.

\subsubsection{Role of Teacher's Expectations}

Positive teacher expectations were associated with high academic performance or academic gains, whereas negative teacher expectations result in decrease in academic performance. The significance of knowing teacher's beliefs regarding their roles in student motivation is crucial due to the accepted correlations between this perception and actions. The quality of teacher-student relationships is the keystone for all other aspects of classroom management (Marzano and Marzano, 2008).

\subsubsection{Environmental Influence}

Reinforcement theorists argue that motivation is in the environment, not in the person such as the teacher (Stipek, 2005). However, it is the teacher who plays the greatest role in setting the atmosphere. Whitaker (2017) argues that it is better to create the relationship that will motivate the student to behave well. School climate and culture will enable or restrict classroom instruction and student learning, since students adapt to their environment if educators create culture where students are expected to succeed (Steward, 2008). Researchers prominent among others, Stewart (2008) suggest that an effective organizational culture can enhance academic achievement and lead to reduced student drop out and failure rate.

\subsubsection{Three Facets of School Climate}

Stewart (2008) identifies three facets of school climate. They are school culture, school organizational structure and the school social structure. The school's culture influences student's connectedness to their environment which researchers suggest affect academic achievement. The 
second element is school organizational structure, which Stewart (2008) uses to describe school and class size both found to lead to posit behavioral and scholastic achievement. The third element Steward (2008) explored was the school's social structure, which includes characteristics such as staff and student ethnicity, gender, socio economic status, teacher skill and preparation.

\subsubsection{Variables Affecting Student-Teacher Relationship and Academic Achievement}

Motivational theorists suggest that student's perception of their relationship with their teacher is essential in motivating students to perform well (Fan and Williams 2010). Students with high self-esteem are more likely to be self-efficacious and set higher goals. Self-esteem also effects student socially (Orth, Robin and Widaman, 2012).

Academic success depends on a variety of factors and these factors can have both positive and negative influence on a child's ability to stay motivated and succeed in school. For children living in a high-poverty, urban environments, there are increased challenges when it comes to succeeding in school (Murray and Malgren 2015)

\subsubsection{Student Characteristics Influencing the Teacher Relationships}

Koles, O'connor and Collins (2013) suggest that student characteristics appear to determine the quality of teacher-student relationships more than teacher characteristics. In terms of gender, research has identified that boys at all grade level have poorer and more conflictual relationship with teachers then girls (Baker, 2006; Koepke and Harkins, 2008; Koles, 2013). Next, that challenges with student relationships from developing (Nurmi, 2012) might be the most obvious factor. Students with chronic behavior problems tends to be on a trajectory of continuous poor teacher-student relationship throughout (Hamre and Piants, 2001; Spilt, 2012).

Furthermore, problem behavior is not just externalizing behavior that is disruptive and harmful to others, but can also be withdrawn internalizing behavior with symptoms such as anxiety and depression (Berry and O'Connor, 2010; Harrisson and Rydell, 2006). Thus, students with conflictual relationship with teachers are more likely to have closeness in their relationships than students with internalizing behaviours (Drugli etal, 2011). This might be because students who openly challenge teachers are at least seeking context while students with internalizing behavior avoid teacher contact (O’Connor and McCartney 2006).

Similarly, Newberry and Davis (2008) found that the close teacher-student relationships of three American Primary School teachers developed a more personal relationship. Unfortunately, withdrawn students seem to have the particular disadvantage of receiving less attention from their teachers than more extroverted students, resulting in lower levels of closeness (Rudasih \& Rimon-Kaufman, 2009; Waell, 2015).Conceptually, the polar characteristics of extrovert and introvert personalities can be defined respectively as being out-going verus shy (Oxford Dictionaries, 2015).

Extroversion has been found to be a personality trait typical of individualist cultures (Hofstede \& McCrae, 2004). Thus, differences between extroverted and introverted student behavior in a multi-cultural classroom might be influenced by student's background in individualist versus collectivist cultures. Thus, Hofstede (1986) describes individualist societies as expecting 
individuals to primarily look after their own and their family's interest while collectivist societies emphasis strong loyalty within a larger group.

Consequently, students with a different cultural background to the teacher might be disadvantaged (Correlius-White 2007, Hoetal, 2012, Kesner, 2008; Roords et al 2011), especially if they are from collectivist cultures high in power distance as they may be less likely to initiate contact with a teacher. If the teacher already has problems with student from a different cultural background, the risk of a negative relationship is magnified (Hoetal 2012), owes and Shivers, 2006). Research further demonstrates that good teacher-student relationship have stronger impact on student outcomes for ethnic minority students than non-minority students (Roorda, 2014). Thus, it is important that teachers working in a multi-cultural school are concerned about developing good relationship with students because students with minority backgrounds depend more on good teacher relationships (Brok et al, 2010, Brok and Levy, 2005).Withdrawn student personalities can include more average students who cannot or do not struggle academically or behaviourally (Newberry 2008). Newberry (2008) therefore refers to them as the forgotten middle (p.96) seen through the lens of attachment theory, the confrontational and withdrawn student personalities reflect insecure relationship patterns (Davis, 2003, Harme \& Piants, 2001). These types of student have also been found to be at-risk of lower self-esteem (Hamre \& Piants, 2001). Thus, such behavior can be indicators of disengagement (Osterman, 2000; Skinner et al., 2008).Precisely, these students depend on the teachers taking responsibility for making contact with them, as research shows that supportive teacher-student relationship boost student confidence in themselves as learners (Skinner et al., 2008, Verschmeren et al., 2013). Research indicates that effective teachers focus on building student self-esteem (kingdom 2012).

This development therefore accentuates the nexus between good teacher-student relationship and student's levels of motivation (Crossman, 2007). While teachers are likely to feel distant to confrontations and withdrawn students, they easily feel close to student's with friendly and polite personalities (Newberry \& Davis, 2008). These students have a secure relationship pattern (Hamre $\&$ Piants, 2001), and they seek contact with the teacher in a positive way. They typically have high levels of academic performance and engagement. (Newberry and Davis, 2008, Newmi, 2012, Patrick et al., 2008). Thus, supporting this view, is research showing that students with learning difficulties tend to have lower quality relationship with teacher (Al-Yagon and Mckulineer, 2004; Roords, 2011). These findings obviously indicate that it might be teacher's liking of high-achieving student that causes good relative with students rather than good relationship causing student outcomes (Cornelius-White, 2007).

It is explicit to establish that the causal direction between teacher-student relationships and student outcomes reveal that the direction of effects is bidirectional (Hughes et al., 2006, Maldonado-Carreno \& Votruba-Drzal, 2011, Skinner \& Belmont, 1993). Thus, student achievement, engagement, and teacher-student relationship, quality are part of a dynamic system of reciprocal influences (Hughes et al., 2008).

\subsubsection{Teacher Characteristics influencing Student Relationship}

Cornelius-White (2007) equates the area of teacher-student relationship to person-centered and learner-centered education models based on humanistic and constructivist theories. Both models 
emphasize teacher qualities such as empathy and warmth (Cornelius-White 2007).Learner-centered education is influenced by client-centered therapy founded by Carl Rogers who claimed that positive teacher student relationships are necessary for effective learning (Cornelius-White 2007). Rogers (1979) argued that in order to create a good learning environment, teachers need to foster three elements in their relationship with students: genuineness, caring and empathic understanding students in classrooms with these teacher attitudes will develop more self-confidence and learn more significantly (Rogers 1979).

Similarly, in literature exploring qualities of good ideal, talented, or export teachers, such teachers are described as caring (Aron and Rechael 2009; Gentry et al, 2011, Hattie, 2003, Hilto, 2011). Interestingly, studies have indicated four themes designing these teachers: they took a personal interest in their students and knew them well; they had high expectations; they made teaching meaningful and relevant and they enjoyed being teachers (Gentry, 2011). Similarly, in Nurmi's (2012) meta-analysis of 19 studies, good teachers were seen as giving praise and having high expectation of their students.

Another quality that is highly valued by students is that teachers use humour to make learning more fun (Arnon and Reichal, 2007; Kington et al, 2012, Muller 1999). Humor serves as a social function and can reduce individuals stress levels (Stuart and Rosenfeld, 1994). Therefore, classroom relationship are strengthened when teachers and student laugh together (Cholewa et al 2012, Hitto 2011). For example, when funny stories or jokes are told (Gentry et al, 2011, Knoell, 2012). Likewise, teachers smiling at students is essential for students feeling that their teacher likes them.

\subsubsection{Talking with Students and Getting to Know Them}

Students describe teachers they value as teachers who know them, who talk and explain, and who listen (Pomeroy, 1998). A starting point for developing good relationship with students is getting to know them in terms of their academic and personal needs, as well as their interest and talents (Arnon \& Reichel, 2009; Aultman et al., 2009; Cholewa, 2012; Gentry, 2011; Harvey, 2012; Isenbarger \& Zembylas, 2006; Muller, 1999; Nigvelt, 2005; Smith \& Strahan, 2004; Ditto, 2012; Worthy \& Patherson, 2001), through talking with them. Getting to know students is important to more beyond labeling students by superficial characteristics. According to labeling theory, labels can affect learning achievement by students performing to teacher's expectations, whether negative or positive (Ercole, 2009). For example, Rosenthal and Jacobson's (1968) well know study Pygmalion in the classroom demonstrated that teacher's expectations of their student's capacities, whether real or not, determine teacher's interactions with students. As a result, students for whom teachers had high expectations performed better, like a self-fulfilling prophecy (Jong ; 2012). Also, if teachers have misleading and low expectations, the danger is that this will negatively affect student's learning (Hattie, 2009), especially if students internalize negative labeling (Ercole, 2009).

This is because students who are negatively labeled tend to feel that they do not belong at school, and respond by disengaging further (Ercole, 2009). Labeling theory is supported by synthesis of effectiveness research showing a strong influence of teacher expectations and labeling of students on academic performance (Hattie, 2009). The evidence indicates that the less teachers know about 
their students, the stronger the effect of labeling and stereotyping on learning (Hattie, 2009). This therefore explains why good teacher-student relationships are a protective factor for student at-risk of school failure (Roords 2011); such as students with behavior problems or learning difficulties for example, if teacher know about the difficult home situation of a disruptive student, they are more likely to develop empathy for the student (O’Connor \& McCartney, 2006).

Consequently, teachers become more, patient and frustration tolerant (Driscoll \& Piants, 2010) and are less likely to refer such students to social education arrangement (Piants, 1995). However, getting to know students and developing empathy for them is a process (Cooper, 2010) and finding time to talk with students individually can be challenging with large class sizes, although synthesized research has only detailed a small effect of class size on learning achievement (Hattie, 2009). On the other hand, other studies have found increased teacher student interaction in small sized classes, positively influencing student engagement (Blatchford et al., 2011; Hollo \& Him, 2015).

However, while initiating interaction with students, it is important for teachers to be aware of the distinction between one-way communication and two-way communication; or between talking to verus talking with students (Tabuber, 2007). In other words, teachers need to practice active listening when talking with students (Cholewa, et al., 2012, Pantic \& Wubbels, 2012; Pomeroy, 1999), because students equate being listened to as a sign of respect (Johnson, 2008). In Davis, (2006) study on the context of relationship quality between American middle-school students and teachers, students described talking with as a kind of informal, personal and meaningful form of talk. When teachers talked to them on the other hand, they felt that this was more important and that they were treated as just another member of class (p.214) students interpreted the latter as damaging to the teacher-student relationship because it made them feel like the teacher did not know them or understand their needs.

Basically, the type of talk teacher engages student in, which can be either academic (Fredrick et al., 2004; Newberry, 2008), makes a difference. For example, Gee (2010) observed that British teachers and students on a residential field trip benefited from opportunities to participate in off task discussions and more informal interactions including sharing a joke. Engaging with teachers in nor academic conservation can lead to closer relationship (Newberry, 2008). Therefore, students who do not get to engage in personal, informal talk with teachers are likely to be disadvantaged. For instance, Hargreases (2014) observed that a British Grade 5 teacher never used humour with her lower achieving students. This might be because teachers tend to focus on being more on task interactions with students who struggle academically as they worry about the student progress (Hargreaves, 2014, Newberry, 2006).

Furthermore, teachers to some extent in a position to use space in engineering encounters and interacting in the teaching environment (Gee, 2015, 2010). However, teacher-student relationships can also evolve as a result of encounter outside of the formal setting (Gee, 2010; Gentry et al., 2011; Ditto, 2012). Experiencing teachers in less formal situations can help humanize teachers can help (Gee, 2012, 2010; Ditto, 2012). This might be because teachers are more likely to share personal information about themselves in informal settings (Gee, 2010). Yet, while some teachers actively use sharing of personal information as a strategy for connecting. 


\section{Research Design}

The design is a survey design. Primarily survey (descriptive survey) viewed opinions of the target population on the impact of the teacher-student relationship and its effects on academic performance with reference to selected Secondary schools in Enugu State. It also specified the target group or population, the appropriate instruments for data collection and analysis.

\subsection{Population of the Study}

The population of the selected secondary schools are shown below in the table:

\begin{tabular}{ll}
\hline Names of the school & $\begin{array}{l}\text { Selected } \\
\text { (students/teachers) }\end{array}$ \\
\hline Okpanku High School & 200 \\
Community Secondary School Nsuka & 186 \\
Community High School Aguobu Owa & 210 \\
Community High School Udi & 220 \\
Boys High School Awgu & 215 \\
Girls High School Nachi & 226 \\
Boys High School Awkananaw & 263 \\
Total & 1,520 \\
\hline
\end{tabular}

Source: Field Survey (2019)

\subsection{Sample and Sampling Technique}

The sample size of this study is 760 . The researcher adopted Taro Yamani sample selection formula to arrive at the figure.

This is obvious in the following procedure:

$$
\text { Formula }=\quad n=\frac{N}{1+N(e)^{2}}
$$

When $\mathrm{n}=$ sample size

$$
\begin{aligned}
& \mathrm{N}=\text { population } \\
& \mathrm{e}=\text { margin of error }
\end{aligned}
$$


$\mathrm{I}=$ constant

$\mathrm{e}=0.05$

$\mathrm{n}=\frac{1,520}{1+1,520(0.05)^{2}}$

$\mathrm{n}=\frac{1,520}{1+1,520(0.025)}$

$\mathrm{n}=\frac{1,520}{1+1}=\frac{1,520}{2}$

$=760$

In other words, the sample size is thus distributed as follows:

Teachers - 380

Students $\quad-\quad \underline{380}$

Total $\quad-\quad \underline{760}$

\subsection{Sampling Technique}

Quota sampling technique was adopted to ensure that a sample that is as closely possible replica of the population were selected. We did not employ randomness in the selection of the sample units. Thus, we ensured that equal number of girls and boys were selected. Same with the teachers to eliminate bias in the responses.

\subsection{Data Collection Instrument}

The instruments used to elicit data from respondents were the questionnaire, and face to face interview. Secondary data were sourced from the library and internet sources.The instrument for data collection which is structured questionnaire items reflects the established research questions. Furthermore, the instrument is divided into section. The instrument consists of options and items in four cluster $\mathrm{A}$ to $\mathrm{D}$ where the respondents were requested to indicate their options on a modified four (4) options. 


\section{Macrothink

Strongly agreed

Agreed

Disagreed

Strongly disagreed

Total

4 points

3 points

2 points

1 point

10 points

\subsection{Method of Data Collection}

The 760 questionnaires were administered directly to the respondents by the Researcher with the assistance of six (6) trained research assistants (who distributed and collected the questionnaire from respondents). Interestingly, the 760 questionnaires were accurately filled and returned. This rare feat is a function of exceptional level of professionalism exhibited by the trained research assistants and civility of the respondents.

\subsection{Method of Data Analysis}

The method of data analysis adopted in analyzing data in this study is the mean which is thus expressed below:

$$
\mathrm{x}=\frac{\mathrm{Fx}}{\mathrm{n}}
$$

Where

$\mathrm{F}=$ frequency

$\mathrm{X}=$ score

$\mathrm{N}=$ Total number of population

The mean is $4+3+2+1=10$

\subsection{Decision Rule}

The decision rule is thus established. If the mean response of the item is 2.5 or above, then the response is accepted. On the other hand, if the mean response is less than 2.5 then the response is rejected. 


\section{Presentation and Analysis of Data}

This chapter presents and analyzed data obtained from the responses.

\section{Research question 1}

To what extent is teachers frequent bullying of students affect their cordial relationship and how has this contributed to dwindling academic performance among secondary school students in Enugu State?

Table 1. Responses on the nature of teacher attitude towards students

\begin{tabular}{|c|c|c|c|c|c|c|c|c|}
\hline \multirow[b]{2}{*}{$\mathrm{S} / \mathrm{N}$} & \multirow{2}{*}{$\begin{array}{l}\text { Questionnaire } \\
\text { items }\end{array}$} & \multicolumn{7}{|c|}{ Responses } \\
\hline & & SA & $\mathrm{A}$ & SD & $\mathrm{D}$ & $\sum \mathrm{FX}$ & $\mathrm{X}$ & Decision \\
\hline \multirow[t]{2}{*}{1} & Teachers in my & - & 152 & 265 & 343 & 1,329 & 1.7 & Rejected \\
\hline & $\begin{array}{l}\text { school are social } \\
\text { and jovial }\end{array}$ & - & 456 & 530 & 343 & & & \\
\hline \multirow[t]{2}{*}{2} & Teachers in my & 160 & 188 & 192 & 220 & 1,808 & 2.3 & Rejected \\
\hline & $\begin{array}{l}\text { school are } \\
\text { receptive and } \\
\text { accommodating }\end{array}$ & 640 & 564 & 384 & 220 & & & \\
\hline \multirow[t]{2}{*}{3} & Teachers in my & 217 & 200 & 254 & 89 & 2,065 & 2.7 & Accepted \\
\hline & $\begin{array}{l}\text { school are strict } \\
\text { and rigid and } \\
\text { brutal. }\end{array}$ & 868 & 600 & 508 & 89 & & & \\
\hline \multirow[t]{2}{*}{4} & Teachers in my & 260 & 205 & 264 & 31 & 2,214 & 2.9 & Accepted \\
\hline & $\begin{array}{l}\text { school are soft } \\
\text { and flexible }\end{array}$ & 1,040 & 615 & 528 & 31 & & & \\
\hline \multirow[t]{2}{*}{5} & Teachers in my & - & 348 & 291 & 121 & 2,095 & 2.7 & Accepted \\
\hline & $\begin{array}{l}\text { school are } \\
\text { controversial } \\
\text { and restive }\end{array}$ & - & 1,392 & 582 & 121 & & & \\
\hline
\end{tabular}

Source: Field Survey, 2019.

Grand mean $\Sigma \frac{x}{x}=\frac{1.7+2.8+2.7+2.9+2.7}{5} \quad 12.3 / 5=2.5$

Table 1 shows the opinion of the respondents (particularly students) on how they perceive teacher's attitude towards students. Information was elicited from the respondents in a cluster of five questionnaire items as contained in items 1,2,3,4 and 5. Thus, the questionnaire items 3,4 and 5 recorded mean above the 2.5 mean bar while option 1 and 2 recorded mean below 2.5. It therefore implied that the respondents have varied reactions on teacher's attitudinal orientation toward students. The calculated 2.5 grand mean equally buttressed the cumulative opinion of the respondents. 


\section{Macrothink}

The findings of the first research question as revealed in the responses of the students in the three selected secondary schools in Enugu State showed that most teachers are strict, rigid, brutal, soft, flexible while others are restive and controversial in relation with students.

\section{Research question 2:}

What are the effects of teacher-student relation on academic performance of students in secondary schools in Enugu State?

Table 2. Responses on the effects on the academic performance

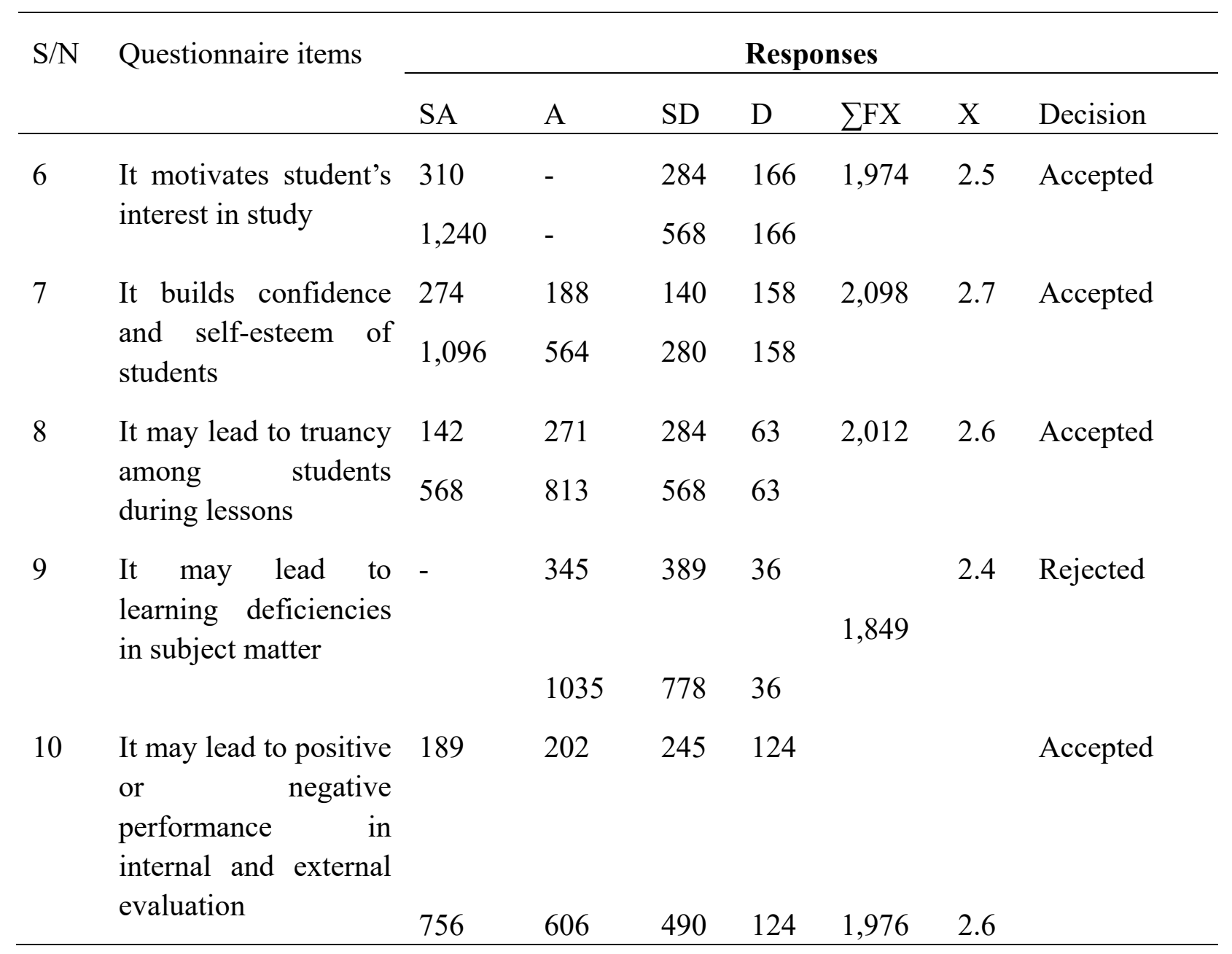

Source: Field Survey, 2019.

Grand mean $\Sigma \frac{x}{\mathrm{w}}=\frac{2.6+2.7+2.6+2.4+2.6}{5} \quad 12.8 / 5=2.5$

Table 2 shows the opinion of the respondents on the effects of teacher-student relation on academic performance. Information was elicited form the respondents in a cluster of five questionnaire items as contained in items 5, 6, 7 and 10 recorded mean below the 2.5 mean bar while option 9 recorded mean bar below 2.5. It further implied that teacher-student relation has both positive and negative effects on academic performance. The calculated 2.5 grand mean 
equally buttressed the cumulative opinion of the respondents

The findings of the second research question as revealed in the responses of the teachers and students in the three selected secondary schools in Enugu State showed that teacher-student relation may positively or negatively affects the academic performance of students. In other words, positive teacher-student relation enhances student's academic performance while adverse teacher-student relation undermines student's academic performance.

\section{Research question 3}

What are the challenges of teacher-student relation in Enugu State?

Table 3. Responses on uncompromising attitude of students

\begin{tabular}{|c|c|c|c|c|c|c|c|c|}
\hline \multirow[t]{2}{*}{$\mathrm{S} / \mathrm{N}$} & \multirow[t]{2}{*}{ Questionnaire items } & \multicolumn{7}{|c|}{ Responses } \\
\hline & & SA & $\mathrm{A}$ & $\mathrm{SD}$ & $\mathrm{D}$ & $\sum \mathrm{FX}$ & $\mathrm{X}$ & Decision \\
\hline \multirow[t]{2}{*}{11} & \multirow{2}{*}{$\begin{array}{l}\text { Negative personality } \\
\text { conception of } \\
\text { teachers }\end{array}$} & 436 & - & 324 & - & 2,392 & 3.1 & Accepted \\
\hline & & 1,744 & - & 648 & - & & & \\
\hline \multirow[t]{2}{*}{12} & \multirow{2}{*}{$\begin{array}{l}\text { Timidity of the } \\
\text { students }\end{array}$} & 278 & 110 & 284 & 88 & 2,098 & 2.7 & Accepted \\
\hline & & 1,112 & 330 & 568 & 88 & & & \\
\hline \multirow[t]{2}{*}{13} & \multirow{2}{*}{$\begin{array}{l}\text { Unfriendly } \\
\text { disposition of the } \\
\text { teachers during and } \\
\text { after lesson }\end{array}$} & 168 & 216 & 342 & 34 & 2,038 & 2.6 & Accepted \\
\hline & & 672 & 648 & 684 & 34 & & & \\
\hline \multirow[t]{2}{*}{14} & \multirow{2}{*}{$\begin{array}{l}\text { Unresentful } \\
\text { of students }\end{array}$} & 288 & 107 & 289 & 337 & 2,388 & 3.1 & Accepted \\
\hline & & 1,152 & 321 & 578 & 337 & & & \\
\hline \multirow[t]{2}{*}{15} & \multirow{2}{*}{$\begin{array}{l}\text { Suspicion and fear of } \\
\text { humiliation between } \\
\text { teachers and students }\end{array}$} & 492 & - & 245 & 23 & 2,726 & 3.5 & Accepted \\
\hline & & 1,968 & - & 735 & 23 & & & \\
\hline
\end{tabular}

Source: Field Survey, 2019.

Grand mean $\Sigma \frac{x}{\mathrm{~s}}=\frac{8 \cdot 1+2.7+2.6+8 i 1+8.16}{5} \quad 15 / 5=3.0$

Table 3 shows the opinion of the respondents on the uncompromising attitude of students and how it affects teacher-student relation. Information was elicited from the respondents in a cluster of five questionnaire items as contained in items 11, 12, 13, 14 and 15. All the questionnaires items, recorded mean above the 2.5 mean bar. This implied that the relationship between teachers and students is fraught with unpleasant relation due to uncompromising attitude of students. The calculated 3.0 grand mean equally buttressed the cumulative opinion of the respondents. 
The findings of the third research question as revealed in the responses of teachers and students in the three selected secondary schools in Enugu State showed that personality conception, timidity, unfriendly disposition, disrespectful attitude, suspicion lead to uncompromising attitude of students and that militate against healthy teacher-student relationship.

\section{Research question 4}

In what ways can teacher-student relationship enhance academic performance?

Table 4. Responses on measures

\begin{tabular}{|c|c|c|c|c|c|c|c|c|}
\hline \multirow[t]{2}{*}{$\mathrm{S} / \mathrm{N}$} & \multirow[t]{2}{*}{ Questionnaire items } & \multicolumn{7}{|c|}{ Responses } \\
\hline & & SA & $\mathrm{A}$ & SD & $\mathrm{D}$ & $\sum F X$ & $\mathrm{X}$ & Decision \\
\hline \multirow[t]{2}{*}{16} & Talking with the & 318 & 243 & 199 & - & 2,399 & 3.1 & Accepted \\
\hline & students after lessons & 1,272 & 729 & 398 & - & & & \\
\hline \multirow[t]{2}{*}{17} & Activating more & 542 & 218 & - & - & 2,822 & 3.7 & Accepted \\
\hline & $\begin{array}{l}\text { interest in student } \\
\text { academic } \\
\text { performance }\end{array}$ & 2,168 & 654 & - & - & & & \\
\hline \multirow[t]{2}{*}{18} & Encouraging students & 298 & 314 & - & 148 & 2,282 & 3.0 & Accepted \\
\hline & $\begin{array}{l}\text { to initiate open } \\
\text { discussion with their } \\
\text { academic plights }\end{array}$ & 1,192 & 942 & - & 148 & & & \\
\hline \multirow[t]{2}{*}{19} & School management & 312 & 400 & - & 48 & 2,496 & 3.2 & Accepted \\
\hline & $\begin{array}{l}\text { advocacy } \\
\text { teacher-student } \\
\text { relation }\end{array}$ & 1,248 & 1,200 & - & 48 & & & \\
\hline \multirow[t]{2}{*}{20} & Enhanced counseling & 481 & 279 & - & - & 2,761 & 3.6 & Accepted \\
\hline & service & 1,924 & 837 & - & - & & & \\
\hline
\end{tabular}

Source: Field Survey, 2019.

Grand mean $\Sigma \frac{x}{\mathrm{w}}=\frac{8.1+8.7+8.0+8.2+8.6}{5} \quad 16.6 / 5=3.3$

Table 4 shows the opinion of the respondents on the measures to enhance academic performance through teacher-student relation. Information was elicited form the respondents in a cluster of five questionnaire items as contained in items 16,17, 18, 19 and 20. All the questionnaires items, recorded mean above the 2.5 mean bar. This implied that the respondents overwhelmingly agreed on the above established measures. The calculated 3.3 grand mean equally buttressed the cumulative opinion of the respondents.

The findings of the fourth research question as revealed in the responses of teachers and students in the three selected secondary schools in Enugu State showed that the measures relevant to strengthen teacher-student relation as regards student's academic performance is a collective responsibility. In this regard, the teacher and student have roles to play in ensuring good teacher-student relation that enhances academic performance. 


\section{Macrothink}

\section{Summary of Findings}

1. Rigidity of teachers influences negatively the relationship of students with them and thus lead to poor academic performance of students

2. Students uncompromising attitude towards teachers affect their relationship with teachers

3. Suspicion among students affects their relationship with their teachers

4. Fostering positive teacher-student relationship is a collective role

\subsection{Conclusion}

This study examined the effects of teacher-student relation on academic performance in secondary schools of Enugu State. The study examined the conceptual and empirical importance, issues and challenges of teacher-student relation and its effects on academic performance. To this extent, the study raised research questions to investigate issues and challenges of teacher-student relation in secondary schools.

Furthermore, the findings revealed that teacher-student relation differ remarkably among student's perception, effects on academic performance with regards to positive and negative trends, challenges militating against academic performance and measures imperative to enhance teacher-student relation. To this extent, the recommendations are the function of the findings as obvious in the responses of the respondents.

\subsection{Recommendations}

Based on the findings of this study, the following recommendations were made:

1. The need for attitudinal change and orientation among teachers towards students. Healthy teacher-student relation begins with the positive orientation and attitude of teachers.

2. The need for students to build confidence in teacher's capacity to find solutions to their academic plights.

3. The need for enhanced supervision of instruction is also fundamental for positive teacher-student relation. In this regard, the principals or head teachers should also intensify supervision of teachers and instructional process as regards student's academic needs.

4. The Enugu state Ministry of Education in collaboration with relevant state education agencies should organize periodic workshop for teachers in Nursery, Primary and Secondary Schools on the imperatives of positive teacher-student relation in academic successes.

5. The School counseling service should also work very efficiently in the trends of teacher-student relation. In this regard, the school counselor should educate students on the benefits of positive teacher-student relation.

\section{References}

Adekunle, L. (2016). Perspectives in Teacher-Student Relation. New York: Longman Inc.

Alnert, L., Harwadt, H., Kappler, G., \& Milatz, A. (2012). Student-Teacher Relationship and 
Classroom Climate in First Grade. Human Development Journal, 14(3), 33-39.

AL-Yagon, M., \& Mikulinear. (2004). Socio-emotional and Academic Adjustment among Children with Learning Disorder: The Mediational Role of Attachment Based Factors. The Journal of Special Education, (9), 30-40.

Anyadike, O. (2015). Issues in Teacher-Student Relation in Nigeria. Onitsha: Education Publishers Inc.

Azubuike, A. (2006). The Challenges of Teacher-Student Relation in Nigeria Open Schools. Calabar: Onix Press.

Baker, J. (2018). Teacher-Student Interaction in Urban at-risk Classrooms. Differential behavior, relationship, quality, and student satisfaction with school. The Elementary School Journal, (100), 57-70.

Baker, M. (2006). Contribution of Teacher-Child Relationship to Positive School Adjustment. Journal of School Psychology, 5(2), 22-45.

Bear, G., Yang, C., Glutting, J., \& Huang, H. (2014). Understanding Teacher-Student Relationship in China and USA. International Journal of Education Psychology, 2(4), 51-65.

Bevis, E. (1990). Has the revolution become the new religion? In Curriculum revolution: redefining the student-teacher relationship. New York: National League for Nursing

Chibuzo, M. (2013). Teacher-Student Relation: A Comparative Analysis. Enugu. Omega-Txco Press.

Cornelius-White, J. (2007). Learner-Centered Teacher-Student Relation: A Meta-Analysis. Journal of Education Review, (4), 50-61.

Davis, H. (2008). Fundamentals of Teaching Method. England: Eaglewood

Davis, H. (2016). Conceptualizing the Role and Influence of Teacher-Student Relation on Children's Social and Cognitive Development. Journal of Education Psychology, (9), 40-48.

Fan, I., \& Williams, O (2010). Perception of teachers and students' commitment to class work. International Journal of Education Psychology, 6(1), 33-41.

Gentry, H. (2011). Fundamentals of Curriculum Design. New York: Macdonald Publishers

Gerry, M. (2011). Theory and Practice of Education Curriculum. New Delhi: Vani Publishers.

Grossman, P., \& McDonald, M. (2018). Back to the future: directions for research in Teaching and teacher education. American Education Research Journal, (45), 184-205.

Gundogdu, K., \& Silman, F. (2007). Teaching as a profession and effective teaching. In Z Cafoglu (Ed.), Introduction to education: Handbook of basic concepts (pp. 259-292). Ankara: Grafiker.

Hargresrs, A. (2000). Mixed Emotions: Teacher's Perception of their Interaction with Students. Journal of Teaching and Teachers. 
Hughes, B. (2006). The Fundamentals of Education Planning, New York: McGraw Hills.

Hughes, B. (2012). Teacher-Student Relationship and School Adjustment Progress. Human Development Journal, (8), 40-49.

Hughes, J. N., Gleason, K. A., \& Zhang, D. (2005). Relationship influences on teachers' perceptions of academic competence in academically at-risk minority and majority first grade students. Journal of School Psychology, (43), 303-320.

Hunt, T. (2005). Motivation and Learning. New York: McGraw Hills

Jong, O. (2012). Effect of Teaching Method on Performance of Students in Taipei Chine. International Journal of Social Development, 4(2), 55-67.

Kim, L. (2016). What education can do in indigent students. International Journal of Curriculum Planning, (5), 33-45.

Koepler, M., \& Harkins, D. (2008). Conflict in the Classroom: Gender Differences in the Teacher-Child Relationship. Early Education and Development Journal.

Koles, B., O’Connor, P., \& Collins, B. A. (2013). Association between Child and Teacher Characteristics and Quality of Teacher-Child Relationship. Journal of European Early Education, (4), 29-31.

Korthegen, A. (2014). Teacher-Student Contract. Teacher-Education Journal, (2), 3-11

Lewis, R. (2011). Classroom Discipline and Student Responsibilities. The Student Review Journal, (4), 41-51.

Marzano, M., \& Marzano, L. (2008). Psychology Themes and Variations. Delhi: Vani Books

Murray, S., \& Malmgren, K. (2015). Teaching the teacher. Journal of Education Management, 6(2), 21-30.

NewBerry, M. (2010). Identified Phases in the Building and Maintaining of Positive Teacher-Student Relation. Journal of Teaching and Teacher.

O’ Connor, E., \& McCartney, K. (2007). Examining Teacher-Child Relationship and Achievement as Part of Ecological Model of Development. American Education Research Journal, (1), 33-45.

O'Connor, E. (2010). Teacher-Child Relationship as Dynamic System. Journal of School Psychology, (9), 23-28.

Orth, R., \& Widaman, O. (2012). Student-teacher relationship, the learning perspective. Journal of Development Education, (9), 51-60.

Pianta, R. (2005). Student-Teacher Relationship Scale. Journal of Education Research, (3), 14-23.

Pomeroy, E. (1999). The Teacher-Student Relationship in Secondary School: Insights from Excluded Students. British Journal of Sociology of Education, (3), 23-31.

Roords, G. (2011). The Principles of Curriculum Design. New Delhi: Vani Publishers 


\section{Macrothink}

International Journal of Regional Development ISSN 2373-9851 2019, Vol. 6, No. 2

Skinner, S., Donald, K., \& Thompson, W. (2008). Education History in Perspective. London: Routledge.

Split, W. (2011). Elements of Sociology. New York: Eaglewood

Stewart, O. (2008). Facets of school climate and learning. Journal of Education Research, 9(3), 24-34.

Stipek, I. (2005). Psychology applied to teaching. New York: Mulfin Publishers

Tanner, C. (1990). Introduction in Curriculum revolution: redefining the student- teacher relationship. New York: National League for Nursing

Verschmeren, S. (2013). Strengthening Education of Facilities in Developing Countries. Journal of Education History, 4(5), 22-34.

Wentzel, K. (2017). Does being good make the grade? Social behavior and academic competence in middle school. Journal of Educational Psychology, (85), 357-364

Whitaker, S. (2013). Variables in the classroom education, the role of the teacher. Journal of Education Psychology, (20), 44-50.

\section{Copyright Disclaimer}

Copyright for this article is retained by the author(s), with first publication rights granted to the journal.

This is an open-access article distributed under the terms and conditions of the Creative Commons Attribution license (http://creativecommons.org/licenses/by/3.0/). 